\title{
BMJ Open Prevalence of multimorbidity in general practice: a cross-sectional study within the Swiss Sentinel Surveillance System (Sentinella)
}

\author{
Sophie Excoffier, ${ }^{1}$ Lilli Herzig, ${ }^{2}$ Alexandra A N'Goran, ${ }^{2}$ Anouk Déruaz-Luyet, ${ }^{2}$ \\ Dagmar $\mathrm{M} \mathrm{Haller}^{1}$
}

To cite: Excoffier S, Herzig L, N'Goran AA, et al. Prevalence of multimorbidity in general practice: a cross-sectional study within the Swiss Sentinel Surveillance System (Sentinella). BMJ Open 2018;8:e019616. doi:10.1136/ bmjopen-2017-019616

- Prepublication history and additional material for this paper are available online. To view these files, please visit the journal online (http://dx.doi. org/10.1136/bmjopen-2017019616).

Received 2 0ctober 2017 Revised 6 December 2017 Accepted 10 January 2018

Check for updates

${ }^{1}$ Primary Care Unit, Faculty of Medicine, University of Geneva, Geneva, Switzerland

${ }^{2}$ Institute of Family Medicine, Lausanne University Hospital, Lausanne, Switzerland

Correspondence to Dr Dagmar M Haller; dagmar.haller-hester@unige.ch

\section{ABSTRACT}

Objectives To estimate the prevalence of multimorbidity using a list of 75 chronic conditions derived from the International Classification for Primary Care, Second edition and developed specifically to assess multimorbidity in primary care. Our aim was also to provide prevalence data for multimorbidity in primary care in a country in which general practitioners (GPs) do not play a gatekeeping role in the health system.

Setting A representative sample of GPs within the Swiss Sentinel Surveillance Network.

Participants 118 GPs completed a paper-based questionnaire about 25 consecutive patients of all ages between September and November 2015. There were no patient exclusion criteria. Recorded data included date of birth, gender and the patients' chronic conditions.

Primary and secondary outcome measures We estimated the prevalence of multimorbidity, defined as $\geq 2$, and $\geq 3$ chronic conditions stratified by gender and age group, and adjusted for clustering by GPs. We also computed the prevalence of each chronic condition individually and grouped by system.

Results Data from 2904 patients were included (mean age $(S D)=56.5(20.5)$ years; male $=43.7 \%$ ). Prevalence was $52.1 \%(95 \% \mathrm{Cl} 48.6 \%$ to $55.5 \%)$ for $\geq 2$ and $35.0 \%$ $(95 \% \mathrm{Cl} 31.6 \%$ to $38.5 \%)$ for $\geq 3$ chronic conditions, with no significant gender differences. Prevalence of two or more chronic conditions was low $(6.2 \%, 95 \% \mathrm{Cl} 2.8 \%$ to $13.0 \%$ ) in those below 20 but affected more than $85 \%$ $(85.8 \%, 95 \% \mathrm{Cl} 79.6 \%$ to $90.3 \%)$ of those above the age of 80 . The most prevalent conditions were cardiovascular ( $42.7 \%, 95 \% \mathrm{Cl} 39.7 \%$ to $45.7 \%)$, psychological $(28.5 \%$, $95 \% \mathrm{Cl} 26.1 \%$ to $31.1 \%$ ) and metabolic or endocrine disorders $(24.1 \%, 95 \% \mathrm{Cl} 21.6 \%$ to $26.7 \%)$. Elevated blood pressure was the most prevalent cardiovascular condition and depression the most common psychological disorder. Conclusion In a country in which GPs do not play a gatekeeping role within the health system, the prevalence of multimorbidity, as assessed using a list of chronic conditions specifically relevant to primary care, is high and increases with age.

\section{INTRODUCTION}

Multimorbidity (MM) is commonly defined as the co-occurrence of two, three or more
Strengths and limitations of this study

- This study provides estimates of the prevalence of multimorbidity based on a sample of patients of all ages from representative practices throughout an entire European country and using a scientifically established list of 75 chronic conditions relevant to multimorbidity in primary care.

- The list was based on codes from the International Classification for Primary Care, Second edition. As some common conditions (ie, chronic renal failure) are missing from this classification, the reported prevalence estimates are somewhat conservative.

- Comparisons with previous studies are limited by the fact that this is the first time this newly established list of chronic conditions relevant to multimorbidity was used to provide prevalence estimates.

chronic conditions (CCs) within one person. ${ }^{1}$ Comorbidity in contrast refers to the development of conditions in addition to one main CC. ${ }^{23}$ The prevalence of MM increases with age, ${ }^{4}$ with an estimated prevalence ranging from $20 \%-30 \%$ in the all-ages population to $55 \%-98 \%$ in individuals over 65 years old. ${ }^{1}$ This represents a significant challenge for current and future healthcare services. MM is most frequently managed in primary care (PC) and $70 \%-80 \%$ of the population visits a general practitioner (GP) at least once a year. ${ }^{56} \mathrm{MM}$ constitutes a growing problem in view of the ageing population and is also associated with increased healthcare costs and threats to quality of care. ${ }^{1}$

Estimates of the prevalence of MM vary significantly depending on various definitions of MM and selected lists with limited numbers of CCs, population settings and data collection methods. ${ }^{1347-10}$ As a consequence, results between studies are difficult to compare. ${ }^{11}$ This was highlighted in 2012 in a systematic review of the literature comparing 
studies in PC settings and among the general population in different geographical regions. ${ }^{7}$

In $\mathrm{PC}, \mathrm{MM}$ is becoming the norm rather than the exception and limited lists of CCs are not representative of daily practice. Yet the number and spread of high or low prevalent CCs is so important that for research purposes it is important to focus on the CCs that are most relevant to MM in PC. Academic investigators developed a list of 75 CCs relevant for MM in PC, based on the International Classification for Primary Care, Second edition (ICPC-2) in a modified RAND method. We believe this is yet the best available list for this setting as the 20 participating experts were experienced and clinically active PC providers. $^{12}$

Furthermore, in the majority of the European countries, GPs act as gatekeepers to the healthcare system. In countries in which this is not the case, such as in Switzerland, Germany or Greece, where patients can directly access specialist care, the prevalence of MM in general practice may be lower. Only few studies conducted in such countries are reported in the literature. In a predominantly rural population in Greece, the prevalence of MM ( $\geq 2$ CCs) in PC was $20.0 \% .{ }^{13}$ Yet there was potentially a participation bias since GPs participated on invitation and worked in specific rural and semirural populations. In a German study, $58.9 \%$ of patients above the age of 65 seen in ambulatory settings had three or more CCs. ${ }^{14}$ Yet these findings were based on insurance claims data and not limited to patients consulting in PC. In Switzerland, one study used electronic data from general practices in a German-speaking region and identified a prevalence of MM ( $\geq 2$ CCs) of $13 \%-15 \%$. Yet there was a high probability of under-reporting in this study since CCs that were not discussed during the consultation were not reported. ${ }^{15}$

In view of these limitations, our aim was to provide estimates of the prevalence of MM in PC in Switzerland, based on the list of 75 CCs relevant for MM. We hypothesised that this prevalence may be lower in a setting in which GPs do not have a gatekeeper role within the healthcare system (as is the case in Switzerland), compared with a setting in which patients need to see a GP to be referred to a specialist. We also hypothesised that the use of a predefined list of CCs relevant to MM in PC would provide us with a more precise estimate of the prevalence of MM in this setting.

\section{METHODS}

\section{Participants and procedure}

This cross-sectional study was conducted from 14 September to 6 November 2015 in general practices across Switzerland. We recruited a voluntary sample of 118 GPs from the Sentinella network, who collected data from 25 consecutive patients attending their practice during a 2-week period. Sentinella is a representative network involving 132 voluntary GPs (and approximately 30 general paediatricians, not included in this study) across Switzerland. The network was initially set up for the epidemiological monitoring of infectious diseases. The Swiss Federal Office of Public Health (FOPH) runs the administrative part of the programme and ensures that GPs are included to be overall representative of all GPs working in Switzerland, and thus also of $75 \%-80 \%$ of the population who visits a GP at least once a year. The Sentinella network also participates in selected research projects. As partner of the network, the FOPH collects data from the GPs registered with the network and ensures they remain anonymous.

\section{Data collection}

For our study, participating GPs were asked to preselect a day within the 2-week study period on which they began data collection for our study. For each patient included in the study, participating GPs completed a paper clinical report form (CRF), which included patients' age and gender and CCs, identified from the list of 75 CCs (described below) ${ }^{12}$ The possibility to add relevant CCs in free text was left to the GPs, to overcome any limitations due to a selected list of CCs. The CRF was a doublesided A4 sheet in which the list of CCs was grouped by main systems in order to facilitate GPs' quick identification of relevant CCs for each patient, thus limiting potential omissions.

All data were anonymised and recorded into a centralised database. All the written communications were made through official letters from the FOPH as per the usual communication of the Sentinella network. This ensured the anonymity of data because there was no contact between the participating GPs and the investigators.

We used the list of 75 CCs developed by N'Goran et $a l$ and recently used in the Multimorbidity in Family Medicine study. ${ }^{12} 16$ This list is based on ICPC-2 and is the result of a four-round modified RAND survey involving a panel of GPs throughout Switzerland to identify the CCs most relevant to MM. ${ }^{17}$

\section{Sample size}

We calculated that a sample size of 2016 patients would be sufficient to measure a prevalence of MM of around $30 \%$ with a precision margin of $2 \%$. Adapting for the clustering of patients within different practices, we used an intraclass correlation coefficient of 0.01 , based on the literature, and estimated a sample size adjusted to 2499, rounded off to 2500 for practical purposes.

\section{Statistical analyses}

A double data entry followed by a reconciliation process was used to ensure the quality of the database. We performed descriptive analyses using Stata V.13 (StataCorp). Patients with missing data for age, gender and/or CCs were excluded. Continuous data (age) were summarised using means and SDs, whereas categorical data were summarised using proportions and CIs, adjusted for clustering within practices. We calculated the 
point prevalence of MM and estimated prevalence of MM by age groups (grouped by steps of 20 years) and by sex. We also computed the prevalence of each CC individually as well as grouped by system.

\section{RESULTS}

\section{Descriptive statistics}

Participation rate was high with 118 of 132 eligible GPs $(89.4 \%)$ in the Sentinella network participating in our study.

The GPs included 2966 patients. Gender information was missing for 54 patients (reported by 29 different GPs) and year of birth for 16 patients (from 13 GPs) including 8 patients for whom both gender and year of birth was missing. Furthermore, one patient was excluded because of missing data concerning CCs. As a result, 2904 patients were retained in the final sample and included in the statistical analysis. $43.7 \%$ were male and mean (SD) age was 56.5 (20.5) years.

The sex and age distribution in our sample was comparable to that of all doctor-patient contacts in the Sentinella network during a similar period (data not shown). We assumed that the minimal differences $(<2 \%)$ in the proportion of individuals in certain age subgroups did not have an influence on the results.

The prevalence of MM independently of age was $52.1 \%$ for two or more CCs and $35.0 \%$ for three or more CCs. Considering the total sample, $27 \%$ did not have any CCs and $1.5 \%$ had more than eight CCs. Prevalence of MM was equally distributed between females and males. Table 1 shows details of the prevalence of two, three or more CCs by gender and age group. The prevalence of MM defined as two or more CCs was $6.2 \%$ in those below the age of 20 years, compared with $44.7 \%, 71.6 \%$ and $85.8 \%$ in the age groups $41-60$ years, $61-80$ years and above 80 years, respectively (table 1 ).

As expected, below the age of 20 , only a minority of patients had a CC $(\mathrm{n}=624,21.5 \%)$. Between 40 and 60 years, about $70 \%$ had at least one CC, and above the age of 80 , the proportion of patients without any CCs was negligible (figure 1).

\section{Distribution by system}

The most commonly reported CCs concerned the cardiovascular system. Psychological disorders, metabolic and endocrine disorders were also common (table 2). The detailed prevalence estimates for all conditions are presented in the online supplementary table.

CCs which contributed most to MM in the age groups 0-20 and 20-40 were psychological conditions and metabolic diseases. Cardiovascular conditions were at the forefront in patients over the age of 40 even though psychological conditions also often contributed to MM in these age groups (figure 2).

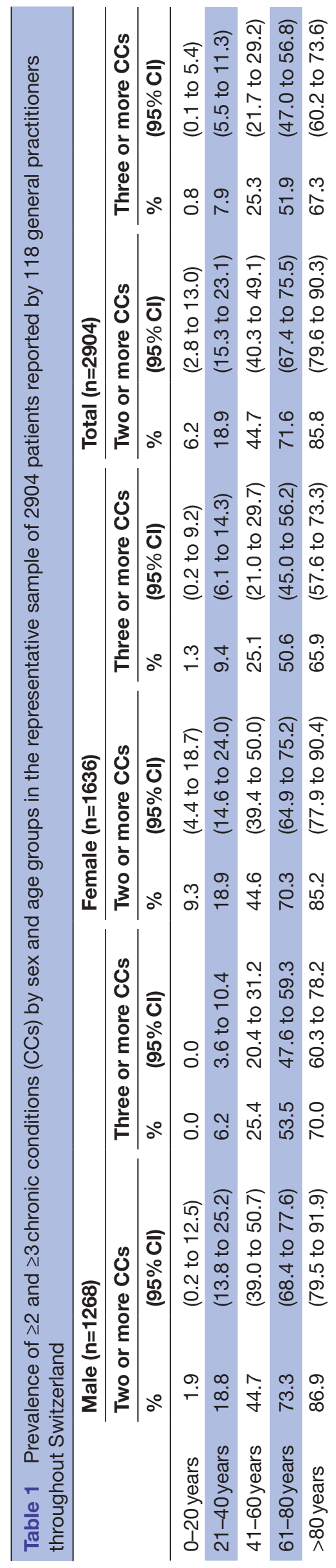


Prevalence by age groups and chronic conditions (cc)

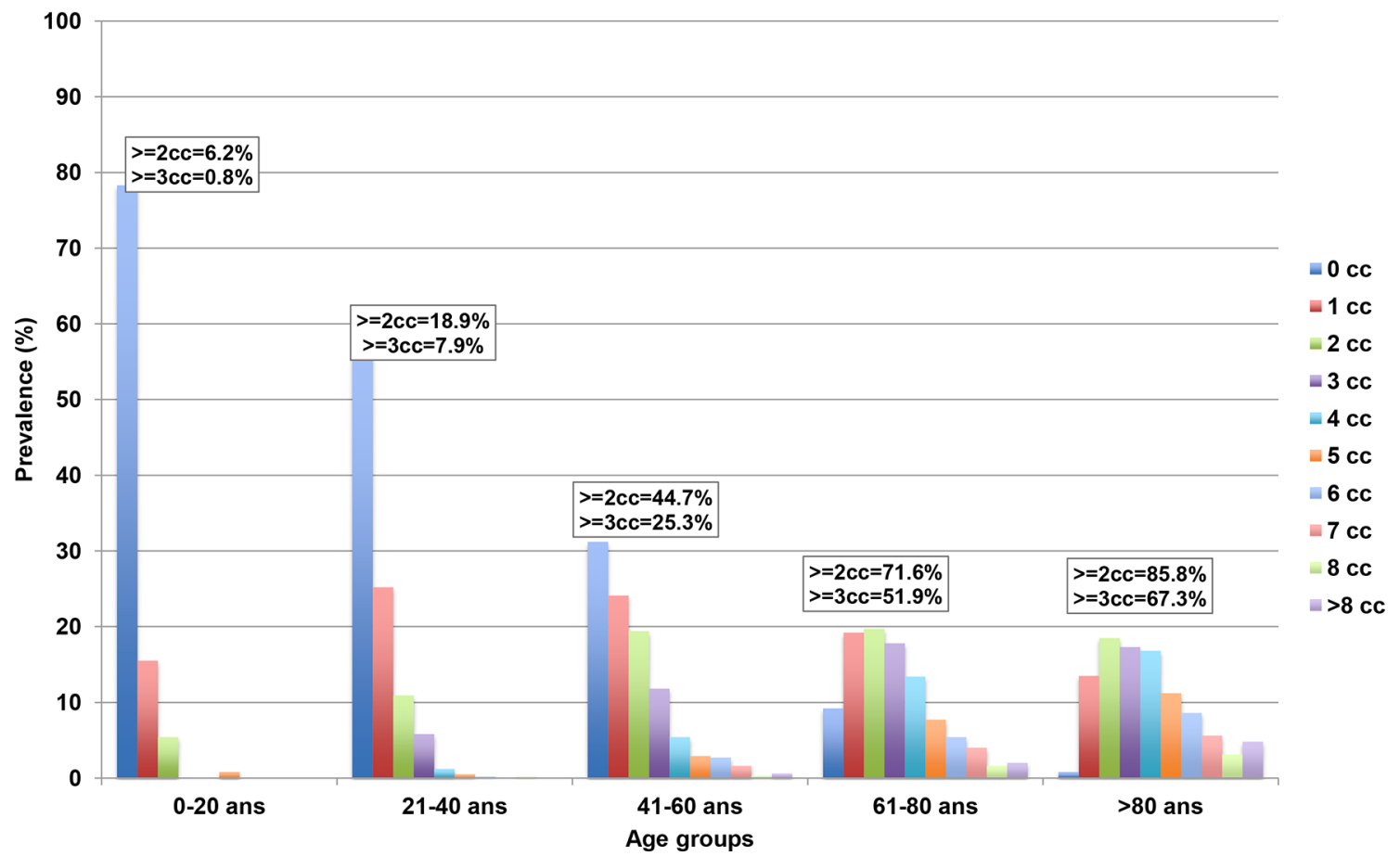

Figure 1 Number of chronic conditions (CCs) by age group in a representative sample of 2904 patients reported by 118 general practitioners throughout Switzerland, and prevalence of multimorbidity in each age group.

\section{DISCUSSION}

\section{Summary of main findings}

Our study highlights the high prevalence of MM in a nationwide cross-sectional study in PC in Switzerland, based on a representative list of CCs relevant for MM. Prevalence of two or more CCs across all age groups was $52.2 \%$, and prevalence of three or more CCs was $35.0 \%$. There were no significant gender differences. As expected, the prevalence of MM increases with age, with about $72 \%$ of patients above 60 years of age having at least two or more CCs, indicating that MM is common in GPs' daily practice, even in a country in which GPs do not have a gatekeeping role within the healthcare system. GPs in our study were more frequently in contact with patients with one or more CCs than without ( $73 \%$ vs $27 \%)$.

The distribution by organ chapter or system highlighted the predominance of cardiovascular diseases mainly due to elevated or high blood pressure with or without complications, which accounted for more than one-third of the conditions. Psychological disorders were prevalent in all age groups and accounted for nearly $30 \%$ of all CCs.

\section{Comparison with the existing literature}

Our prevalence estimates are much higher than that described in a previous study conducted in Switzerland, based on data extracted from electronic medical records, in which prevalence of MM was 15\% (Family Medicine ICPC Research using electronical medical records (FIRE) study). ${ }^{15}$ Under-reporting of CCs not actively treated in the consultation may possibly explain the low prevalence of MM in this study. Similarly, under-recording in electronic medical records may explain the lower prevalence of MM measured as two or more CCs (23.2\%) in another study involving more than 300 practices in Scotland. ${ }^{4}$ In addition, in the Scottish study, the CCs were identified within a list of 40 conditions established by the authors, and were not based on the ICPC-2. Thus, these findings are not directly comparable with ours. Studies from the Netherlands used lists based on ICPC-2. In a Dutch study using a list of $28 \mathrm{CCs}$ within this classification, prevalence of MM defined as two or more CCs in patients above the age of 55 years was $37 \% .{ }^{18}$ This is surprisingly low compared with our findings, particularly if one considers that younger patients were excluded. Again, under-reporting due to extraction limited to active CCs within electronic medical files, may explain this low prevalence as well as the limited number of CCs to choose from within the list these authors used. A reference group outside of Europe (Fortin $e t a l$ ) reported prevalence estimates of two or more CCs of $98.7 \%$ in patients above the age of $65 .^{5}$ In this study, no preselected list of CCs was used. The practitioners had the possibility of reporting any conditions they considered chronic and this may have increased the spectrum of disorders potentially contributing to MM in this study. The same authors reported strong differences in estimated prevalence according to variations in the methodology of the study, particularly with regard to the number of CCs. ${ }^{7}$ In a recent substudy of the national survey Bettering the Evaluation and Care of Health in Australia, a prevalence of around $50 \%$ for two or more CCs and 27\% for three or more CCs in a family medicine sample was estimated, similar to our findings. ${ }^{19}$ 
Table 2 Prevalence of chronic conditions (CCs) in the representative sample of 2904 patients (presenting only CCs with a prevalence $\geq 5 \%$ in one gender)

\begin{tabular}{|c|c|c|c|c|c|c|c|}
\hline \multirow[b]{2}{*}{ CCs } & \multirow[t]{2}{*}{$\begin{array}{l}\text { ICPC- } \\
2 \text { code }\end{array}$} & \multicolumn{2}{|c|}{ Male $(n=1268)$} & \multicolumn{2}{|c|}{ Female $(n=1636)$} & \multicolumn{2}{|c|}{ Total $(n=2904)$} \\
\hline & & $\%$ & $(95 \% \mathrm{Cl})$ & $\%$ & $(95 \% \mathrm{Cl})$ & $\%$ & $(95 \% \mathrm{Cl})$ \\
\hline \multicolumn{8}{|l|}{ Cardiovascular diseases } \\
\hline $\begin{array}{l}\text { Hypertension } \\
\text { uncomplicated }\end{array}$ & K86 & 20.7 & (17.8 to 23.9$)$ & 19.4 & (16.9 to 22.3 ) & 20.0 & (17.6 to 22.6 ) \\
\hline Elevated blood pressure & K85 & 14.0 & (11.2 to 17.3$)$ & 10.8 & (8.4 to 13.7$)$ & 12.2 & (9.9 to 14.9 ) \\
\hline $\begin{array}{l}\text { Risk factor cardiovascular } \\
\text { disease }\end{array}$ & K22 & 13.1 & (10.3 to 16.5$)$ & 10.4 & (7.9 to 13.6$)$ & 11.6 & (9.2 to 14.5$)$ \\
\hline Atrial fibrillation/flutter & K78 & 7.0 & (5.6 to 8.8$)$ & 6.3 & (5.0 to 7.9$)$ & 6.6 & (5.6 to 7.8 ) \\
\hline $\begin{array}{l}\text { Ischaemic heart disease } \\
\text { without angina }\end{array}$ & K76 & 6.9 & (5.5 to 8.7$)$ & 3.7 & (2.7 to 4.9$)$ & 5.1 & (4.2 to 6.2$)$ \\
\hline Atherosclerosis & K92 & 6.4 & (5.0 to 8.1$)$ & 3.7 & (2.9 to 4.8$)$ & 4.9 & (4.1 to 5.8 ) \\
\hline Cerebrovascular disease & K91 & 5.1 & (3.9 to 6.8$)$ & 3.0 & (2.1 to 4.2$)$ & 3.9 & (3.1 to 4.9 ) \\
\hline \multicolumn{8}{|c|}{ Endocrine/metabolic and nutritional } \\
\hline Obesity & T82 & 13.6 & (11.2 to 16.5$)$ & 16.8 & (14.1 to 19.9$)$ & 15.4 & (13.3 to 17.9$)$ \\
\hline $\begin{array}{l}\text { Diabetes non-insulin } \\
\text { dependent }\end{array}$ & T90 & 13.0 & $(11.0$ to 15.4$)$ & 8.3 & (6.8 to 10.1$)$ & 10.4 & (9.0 to 11.9$)$ \\
\hline \multicolumn{8}{|l|}{ Psychological } \\
\hline Depressive disorder & P76 & 9.4 & (7.6 to 11.5$)$ & 14.9 & (13.0 to 17.1$)$ & 12.5 & (10.9 to 14.3 ) \\
\hline \multicolumn{8}{|l|}{ General and unspecified } \\
\hline $\begin{array}{l}\text { Pain general/multiple } \\
\text { sites }\end{array}$ & $\mathrm{A} 01$ & 6.9 & (5.3 to 9.0$)$ & 10.5 & (8.7 to 12.7$)$ & 9.0 & (7.5 to 10.7$)$ \\
\hline \multicolumn{8}{|l|}{ Musculoskeletal } \\
\hline Osteoarthritis of knee & L90 & 6.1 & (4.8 to 7.6$)$ & 9.4 & (7.7 to 11.5$)$ & 8.0 & (6.7 to 9.4$)$ \\
\hline Osteoarthritis of hip & L89 & 4.4 & (3.2 to 6.1$)$ & 7.7 & (6.2 to 9.5$)$ & 6.3 & (5.1 to 7.7$)$ \\
\hline Osteoporosis & L95 & 0.9 & (0.5 to 1.7$)$ & 7.6 & (6.2 to 9.3$)$ & 4.7 & (3.9 to 5.8 ) \\
\hline \multicolumn{8}{|l|}{ Respiratory } \\
\hline $\begin{array}{l}\text { Chronic obstructive } \\
\text { pulmonary disease }\end{array}$ & R95 & 5.0 & (3.8 to 6.5$)$ & 3.6 & (2.7 to 4.8$)$ & 4.2 & (3.4 to 5.1 ) \\
\hline
\end{tabular}

ICPC-2, International Classification for Primary Care, Second edition.

Unlike in other health systems, GPs in Switzerland generally do not have a gatekeeper role and patients can have direct access to specialists. We hypothesise that a number of patients with only one CC may tend to only see a specialist. However, as the complexity of managing CCs increases, we can expect that a more holistic management will require a GP. Therefore, we hypothesise that in the Swiss healthcare system, the more CCs a patient has, the more likely it is that they will be managed by a GP rather than a specialist. This could lead to a selection of patients, in turn resulting in a higher prevalence of MM in PC, as observed in our study. Alternatively, patients with more CCs may more often require coordination of specialised care through the GP.

In our study, prevalence of two or more CCs in the 0-20 age group was $6.2 \%$ and close to $90 \%$ in patients above 80 years old. Thus, MM is associated with age, but not gender, which is consistent with others studies. ${ }^{1520}$
The main CCs reported in the literature are cardiovascular diseases, diabetes, chronic kidney disease, osteoarthritis, chronic lung diseases, mental disorders (depression, dementia). ${ }^{21}$ Our results are consistent with a majority of conditions involving the cardiovascular system. However, our prespecified list of chronic disorders did not include disorders such as back and cervical pain specifically. GPs could either report the latter as general pain or add a commentary at the end of the form. Thus, the contribution of these disorders to the overall prevalence may have been underestimated.

The prevalence of cardiovascular diseases and endocrine and metabolic diseases was 20-40 times higher in those above the age of 80 years compared with the youngest age group. Psychological disorders were only about three times more prevalent in older age groups, in line with previous studies reporting high prevalence of mental disorders in young persons. ${ }^{22}$ 
1800

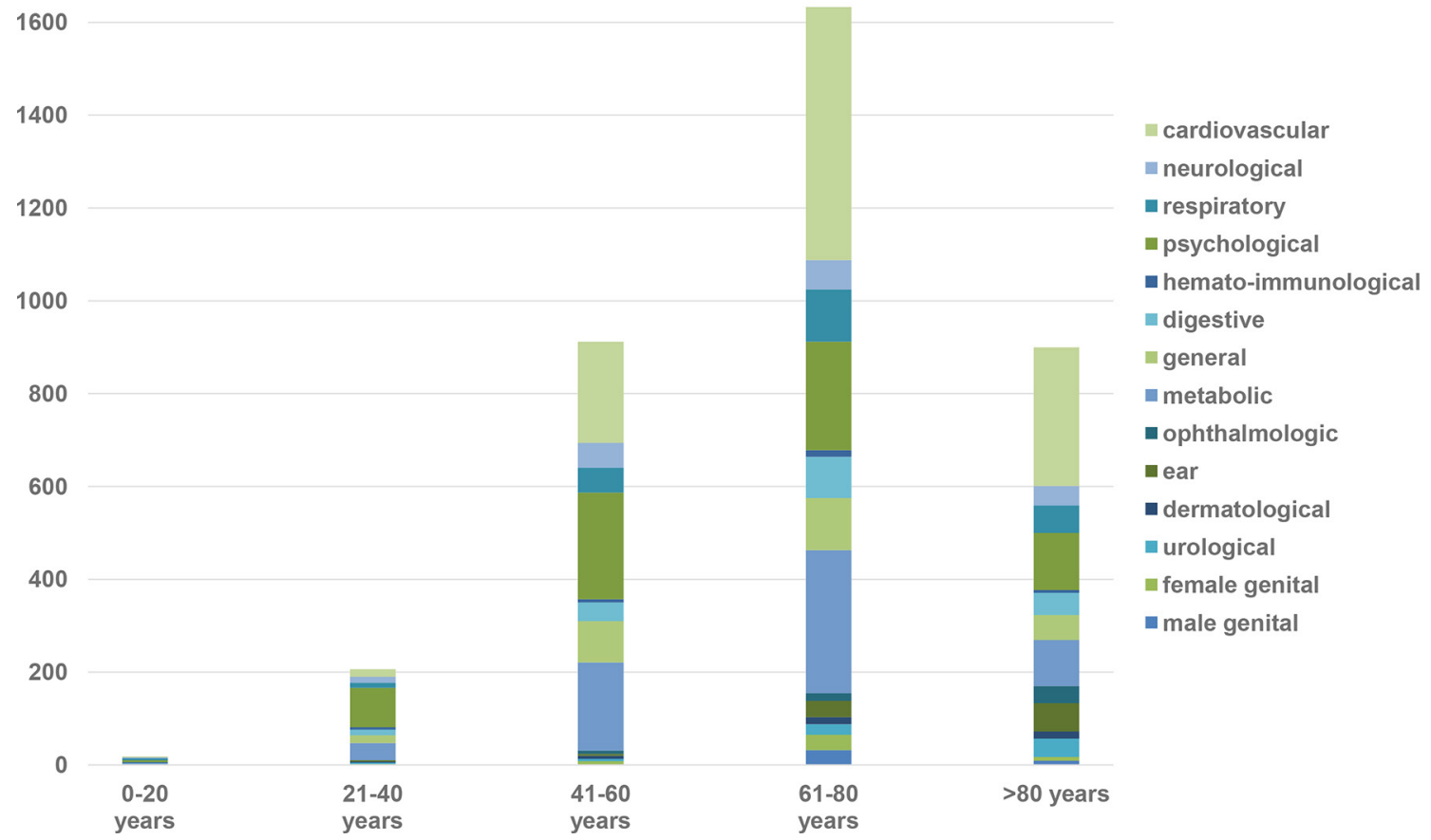

Figure 2 Spread across systems of chronic conditions contributing to multimorbidity, by age group, in 2904 primary care patients.

\section{Strengths and limitations}

A main strength of the current study is that our data were collected from a representative sample of practices throughout an entire country and using a scientifically established list of 75 CCs relevant to MM in PC. This list is a result of a consensus process between experts in general practice to identify the CCs that are most relevant to MM in PC. ${ }^{12}$ It provides an estimate based on the daily reality of GPs, and adds strength to the validity of the selected list.

Our inclusion criteria did not exclude any age category, which enabled us to estimate prevalence among young people, contrary to the majority of other studies that have only been interested in patients above the age of 50 or 65 years.

There was no participation bias as every consecutive patient was included.

Our study has certain limitations. First, our estimate was rather conservative, as reported CCs were preselected. This may have led to an underestimation of MM, as it has been suggested that prevalence of MM is highly dependent on the number of CCs included in the definition. ${ }^{1123}$ Some GPs added conditions at the end of the form if they had not found them in the prespecified list. These were too heterogeneous to be counted in the MM prevalence estimates, which were thus based exclusively on the 75 predefined CCs. Second, some CCs (chronic renal failure) were missing from the ICPC-2, and thus from our selection. In addition, other CCs, such as thyroid diseases, degenerative diseases, chronic hepatitis, were not part of our selected list of CCs. Third, we used a newly created list of CCs. ${ }^{12}$ This could compromise the external validity of our study, since no exact comparison with previous prevalence studies could be done. However, this list was developed specifically for PC following a rigorous methodology. Its previous use to characterise a sample of multimorbid patients in PC led to similar distributions of CCs (although as this previous study involved only multimorbid patients, no prevalence data could be extracted). ${ }^{16}$ GPs from all parts of Switzerland, practising in three culturally diverse regions of the country, were involved in the development of this list. Since the epidemiological profile of MM is likely to be similar in other high-income countries, the list is likely to be relevant for studies in most other high-income countries.

Fourth, the definition of CCs such as elevated blood pressure was left to the appreciation of GPs and CCs such as cardiovascular risk factors may be redundant with obesity, high blood pressure or tobacco use. In addition, GPs who were not familiar with ICPC-2 codes may have miscoded some items, thus leading to reporting bias. In particular, we cannot exclude that some GPs may have recorded family history or age, as a cardiovascular risk factor. Fifth, we cannot differentiate whether reported CCs were active health problems or not. GPs may have reported important CCs which no longer had an impact on the patient's current health, such as cancer treated in the past. Finally, that no general paediatricians (who are PC providers in Switzerland) participated in our study may have led to an underestimation of the prevalence of MM in the age group 0-20 years old. 


\section{Implications for practice and research}

Our findings highlight that even in a country in which GPs do not have a gatekeeping role, caring for patients with $\mathrm{MM}$ is at the forefront of their activity. In the context of a high prevalence of MM as estimated in our study, diseasebased management is no longer possible and developing new models of care is essential. This has implications for service planning (including thoughts about pricing) and for pregraduate and postgraduate training.

A fundamental concept is the global impact of MM on quality of care, and complexity of care, that could be more accurately assessed by a validated morbidity index rather than by adding CCs together. Future studies need to specify which combination of CCs or patients' characteristics are associated with higher needs and impacts on quality of care, morbidity and mortality. This could help us identify subgroups of patients who could benefit the most from new models of care.

\section{CONCLUSIONS}

MM is highly prevalent among patients consulting GPs in Switzerland. These results have implications for training and the organisation of healthcare in our country. The identification of the patients most likely to benefit from complex care within family practice, and the development of new models of care to address their needs are challenges for the future.

Acknowledgements The authors thank the Sentinella network commission for their support and scientific input, and all the reporting GPs from the programme who participated in our study. This study is part of the MMFM (multimorbidity in family medicine) research programme coordinated by the five Swiss University Institutes of Family Medicine within SAFMed (Swiss Academy of Family Medicine). We also thank Jennifer Hasselgard-Rowe for her help in editing the manuscript.

Contributors SE, DMH, LH, AD-L and AAN designed and elaborated the protocol, AAN, LH and AD-L collected the data, SE and DMH conducted the data analyses; all authors contributed to the interpretation of the data. SE provided the first draft of the manuscript, that was revised, read and approved by all authors.

Funding This study was supported by funds granted by the Swiss University Conference to reinforce teaching and research in primary care in Switzerland as part of the masterplan for family medicine (SUC-P10).

Competing interests None declared.

Patient consent Not required.

Ethics approval Since the study involved the analysis of completely anonymous data, it was granted a waiver from approval by the Human Research Ethics Committee of the Canton Vaud.

Provenance and peer review Not commissioned; externally peer reviewed.

Data sharing statement Extra data are available by emailing dagmar.hallerhester@unige.ch.

Open Access This is an Open Access article distributed in accordance with the Creative Commons Attribution Non Commercial (CC BY-NC 4.0) license, which permits others to distribute, remix, adapt, build upon this work non-commercially, and license their derivative works on different terms, provided the original work is properly cited and the use is non-commercial. See: http://creativecommons.org/ licenses/by-nc/4.0/

(C) Article author(s) (or their employer(s) unless otherwise stated in the text of the article) 2018. All rights reserved. No commercial use is permitted unless otherwise expressly granted.

\section{REFERENCES}

1. Glynn LG, Valderas JM, Healy P, et al. The prevalence of multimorbidity in primary care and its effect on health care utilization and cost. Fam Pract 2011;28:516-23.

2. Feinstein AR. The pre-therapeutic classification of co-morbidity in chronic disease. J Chronic Dis 1970;23:455-68.

3. Marengoni A, Angleman S, Melis R, et al. Aging with multimorbidity: a systematic review of the literature. Ageing Res Rev 2011;10:430-9.

4. Barnett K, Mercer SW, Norbury M, et al. Epidemiology of multimorbidity and implications for health care, research, and medical education: a cross-sectional study. Lancet 2012;380:37-43.

5. Fortin M, Bravo G, Hudon C, et al. Prevalence of multimorbidity among adults seen in family practice. Ann Fam Med 2005;3:223-8.

6. Office fédéral de la statistique. Santé: Statistique de poche. Neuchâtel: Office fédéral de la statistique, OFS, 2015.

7. Fortin M, Stewart M, Poitras ME, et al. A systematic review of prevalence studies on multimorbidity: toward a more uniform methodology. Ann Fam Med 2012;10:142-51.

8. Muggah E, Graves E, Bennett C, et al. The impact of multiple chronic diseases on ambulatory care use; a population based study in Ontario, Canada. BMC Health Serv Res 2012;12:452.

9. Brett T, Arnold-Reed DE, Popescu A, et al. Multimorbidity in patients attending 2 Australian primary care practices. Ann Fam Med 2013;11:535-42.

10. Wolff JL, Starfield B, Anderson G, Prevalence AG. Prevalence, expenditures, and complications of multiple chronic conditions in the elderly. Arch Intern Med 2002;162:2269-76.

11. Fortin M, Hudon C, Haggerty J, et al. Prevalence estimates of multimorbidity: a comparative study of two sources. BMC Health Serv Res 2010;10:111.

12. N'Goran AA, Blaser J, Deruaz-Luyet A, et al. From chronic conditions to relevance in multimorbidity: a four-step study in family medicine. Fam Pract 2016;33:439-44.

13. Minas M, Koukosias N, Zintzaras E, et al. Prevalence of chronic diseases and morbidity in primary health care in central Greece: an epidemiological study. BMC Health Serv Res 2010;10:252.

14. van den Bussche $\mathrm{H}$, Schön $\mathrm{G}$, Kolonko T, et al. Patterns of ambulatory medical care utilization in elderly patients with special reference to chronic diseases and multimorbidity--results from a claims data based observational study in Germany. BMC Geriatr 2011;11:54.

15. Rizza A, Kaplan V, Senn O, et al. Age- and gender-related prevalence of multimorbidity in primary care: the Swiss FIRE project. BMC Fam Pract 2012;13:113.

16. Déruaz-Luyet A, N'Goran AA, Senn N, et al. Multimorbidity and patterns of chronic conditions in a primary care population in Switzerland: a cross-sectional study. BMJ Open 2017;7:e013664.

17. Classification Committee of the World Organization of Family Doctors (WICC). ICPC-2: International Classification of Primary Care. Oxford University Press: Oxford, 1997.

18. van Oostrom SH, Picavet HS, van Gelder BM, et al. Multimorbidity and comorbidity in the Dutch population-data from general practices. BMC Public Health 2012;12:715.

19. Harrison C, Henderson J, Miller G, et al. The prevalence of complex multimorbidity in Australia. Aust N Z J Public Health 2016;40:239-44.

20. Britt HC, Harrison CM, Miller GC, et al. Prevalence and patterns of multimorbidity in Australia. Med J Aust 2008;189:72-7.

21. Fraccaro P, Arguello Casteleiro M, Ainsworth J, et al. Adoption of clinical decision support in multimorbidity: a systematic review. JMIR Med Inform 2015;3:e4.

22. Schuler D, Burla L. La santé psychique en Suisse. Monitorage 2012. Neuchâtel: Observatoire suisse de la santé, OBSAN, 2012. Contract No: Obsan rapport 52.

23. Schneider F, Kaplan V, Rodak R, et al. Prevalence of multimorbidity in medical inpatients. Swiss Med Wkly 2012;142:w13533. 